\title{
Performance Evaluation in Sustainability Conscious Manufacturing Companies by Using TOPSIS Method
}

\author{
Merve Kılıç and Seren Özmehmet Taşan \\ Dokuz Eylul University, Department of Industrial Engineering, Izmir, Turkey \\ mervekilic_35_5@yahoo.com \\ seren.ozmehmet@deu.edu.tr
}

\begin{abstract}
In a manufacturing environment, managing limited resources has always been a main issue for engineers. Recently, the idea of managing limited resources without harming ecological environment adopted by manufacturing sector and sustainable manufacturing has become a key issue. While the concept of sustainability has been recognized, companies need to measure how sustainable they perform. Therefore, sustainability indicators are developed and used in order to assess companies' production activities expediently to sustainable manufacturing. This paper presents a research indicating the application of TOPSIS method on sustainability indicators related to production for two different multi-criteria decision making problems in a sustainability conscious manufacturing company.
\end{abstract}

Keywords: Sustainability, Indicator, Manufacturing, TOPSIS, Performance Evaluation.

\section{$1 \quad$ Introduction}

In ecology, sustainability is defined as the providing the continuousness of biological systems' variety and productivity. Considering this definition, the term of sustainability is used for managing the resources via long term maintenance of responsibility for environment, economy and society. Sustainability can be evaluated as a problem statement that seeks ways for human and other forms of life will flourish on the planet forever. With the ever increasing interest in sustainability, the companies started to realize the importance and impact of manufacturing their products in a more sustainable way. Sustainable manufacturing refers to that decreasing the negative effects of a product and its production processes on environment, health and welfare of community to minimum level. From raw material to the finished good and even at the recycling phase, the product should cause no or minimum damage to environment and during its production process, environmental resources should be used efficiently. The objectives of sustainable manufacturing are defined by the European Union as creating more value for more (growth) and better jobs, increasing the competition of European industries and the communities in the knowledge century and sustainable development of economies [1]. Since the importance of the sustainable manufacturing has been increased rapidly, companies 
show tendency to adopt this concept. Similar to companies' approach which uses financial indicators to determining the business success, there has been needed to measure and evaluate sustainability. However, sustainability can be thought as an abstract concept which is hard to measure. Therefore sustainability indicators are developed and used in order to measure how a company succeeds in the concept of sustainability and sustainable production.

Several researchers have focus on determining indicators for sustainable manufacturing [2-4]. These researchers gave utmost importance to create and define new sustainable manufacturing indicators. However, due to difficulties in determining suitable indicator baseline, there has been a lack of research concerning performance evaluations by using indicators. Practically, various indicators should be considered simultaneously while evaluating the sustainability performance of a manufacturing system. In order to fill this gap, the contribution of this study focuses on the application of TOPSIS method that makes us able to consider various sustainability indicators simultaneously. The remainder of this paper is organized as follows; Section 2 presents the necessary background information regarding to sustainability indicators while focusing on the product indicators. Following, section 3 consists of the brief explanation of the TOPSIS method. Later, section 4 includes the application of TOPSIS method on two different case studies. Finally, conclusions and directions for future researches are given in section 5 .

\section{Sustainability Indicators Related to Manufacturing}

The indicator has significance that extends beyond the properties directly associated with the parameter values. Indicators possess a synthetic meaning and are developed for a specific purpose [2]. United Nations (UN) defined indicators for sustainable development considering sociological field of development problems as well as the physical problems [5]. UN grouped indicators according to fields such as poverty, governance, health, education, demographics, natural hazards, atmosphere, land, oceans, seas and coasts, freshwater, biodiversity, economic development, global economic partnership, consumption, and production. In literature, sustainability indicators related to manufacturing are evaluated in three differently named groups such as product, process and management [3]; social, environmental and economic [4] or inputs, operations and products [2]. This paper presents only the indicators related to product. Indicators related with product generally state the impacts of materials used for producing the product, consumption and renewability of the resources used for production and recyclability of a product.

Neto et al. [3] defined nine indicator related to product considering the material usage and renewability, usage of resources such as energy and water and transportation of material and products. Similar to this study, OECD [2] defined product indicators related to materials with the aspects of renewable and nonrenewable and also with the content of restricted substance. Energy consumption is also included in to indicators and as an addition; greenhouse gas emission intensity is mentioned. Krajnc and Glavic [4] defined product indicators under the output indicators which is a branch of the main title of the environmental indicators. Additionally, they considered the recyclable materials. 


\section{TOPSIS Method}

TOPSIS stands for technique for order preference by similarity to ideal solution developed by Hwang and Yoon [6]. TOPSIS method has several advantages; one of which is the application convenience and simplicity when identifying the suitable alternative quickly. Additionally, it performs similar to various methods that use additive weights and performs better than other methods in most cases.

The TOPSIS method based on the selected alternative should to be found at the shortest distance from the positive ideal solution and farthest from the negative ideal solution. Positive ideal solution represents the best criteria values and conversely the negative ideal solution represents the worst criteria values attainable from all alternatives. TOPSIS can be summarized in six steps (Fig.1). In first step, evaluation matrix is built by listing alternative horizontally and criterions vertically. Second step consists of dividing each center values by the norm of the total outcome vector in order to non-dimensionalize the center values in the evaluation matrix. Third step includes multiplying the matrix's values by normalized weights of each criterion and establishing the relative importance matrix. The fourth step consists of building positive and negative ideal solutions to compare the alternatives with each other. After determining the positive and negative ideal solutions, the separation of each matrix value from the ideals are measured as Euclidean distances in the fifth step. At the sixth step, these distances are transformed into a single metric called relative closeness to the ideal solution. Finally, alternatives ranked according to their closeness to the ideal solution.

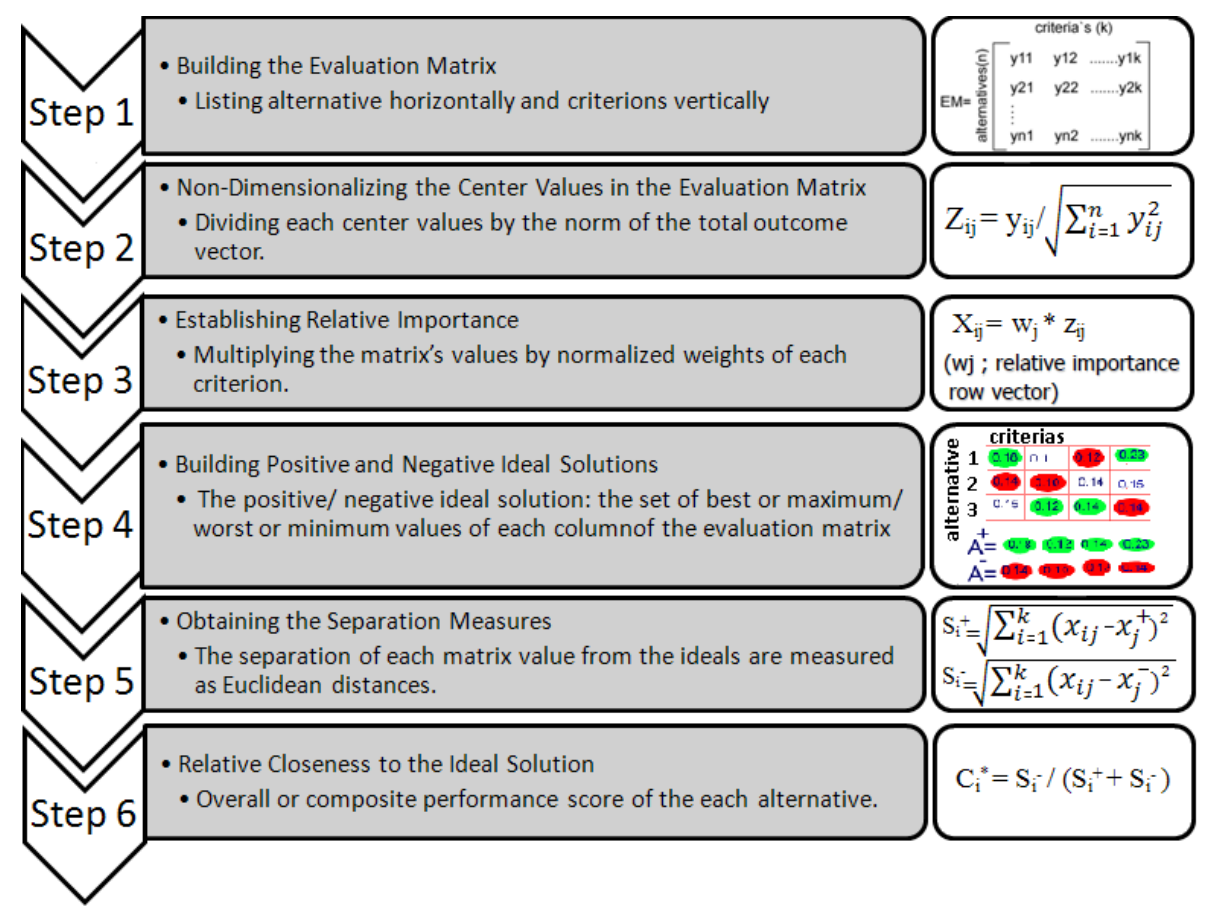

Fig. 1. Summary of TOPSIS steps 


\section{Case Studies}

In order to present the applications of multi-criteria decision making process for evaluating sustainability indicators in the concept of manufacturing, two different case studies are formed and examined according to company's perception of sustainability. The first case study includes the application of TOPSIS method on the decision making regarding six production period of the company concentrating on three sustainability indicators: product durability, revenues from eco-products and reusable packaging mass. After applying steps mentioned in section 3, the most appropriate period with the strategy that fits to the company's criterions are determined. The second case study includes determining that which product is matched with the firm's philosophy of sustainability. Six eco-products are examined based on the four criterions and the most preferable product with the maximum revenue, shortest production time, involves larger amount of recyclable material and with minimum amount of carbon emission is determined as a result of the study. After applying steps mentioned in section 3, the most appropriate eco-product that fits to the company's perception of sustainability is determined. Finally, results for both case studies are discussed in detail.

\subsection{Case Study I}

This case study concerns with the sustainability performance in Company X over time periods. While producing their ordinary goods the firm decided to enlarge its product range to the new segment: eco-products. During 6 time periods they have been trying to develop a production strategy related to their sustainability perception. Now Company $\mathrm{X}$ wants to eliminate the production of ordinary products and focus on the eco-products. The firm concentrates on 3 sustainability indicators: product durability $\left(\mathrm{I}_{1}\right)$, revenues from eco-products $\left(\mathrm{I}_{2}\right)$ and reusable packaging mass $\left(\mathrm{I}_{3}\right)$. They observed the information related these indicators and examined the 6 time periods (see Fig. 2, step 1). There were 6 different strategies in 6 time periods and now the firm wants to evaluate that which strategy is better. According to sustainability policy of Company $\mathrm{X}$, it is better if a product has maximum durability, consists of more reusable package and with the maximum revenue.

Using the information gathered by Company $\mathrm{X}$ for 3 sustainability indicators over 6 time periods, TOPSIS method was applied as shown in Fig. 2 and summarized in Fig. 3. The results of TOPSIS showed that the strategy applied on the $6^{\text {th }}$ period fits best to the Company X's sustainability perception and the firm decided to continue its production activities with this strategy. Performance criterion of $5^{\text {th }}$ period is very close to period 6. From Fig. 3 , it is seen that the durability is achieved in $5^{\text {th }}$ and $6^{\text {th }}$ period to 8 years and revenue obtained from eco-products shows small decrease. It is also seen that the reusable packaging mass is doubled from period 5 to 6 . If the firm concentrates on only first 4 periods, it would be difficult to make a choice because the results provided from these periods are very close to each other while data belongs to these periods were varied. 


\subsection{Case Study II}

This case study concerns with the sustainability performance in Company $\mathrm{X}$ for various products. Company $\mathrm{X}$ wants to determine that which product is matched with the firm's policy of sustainability. The relevant data regarding to six products A, B, C,

Step 1: Building the Evaluation Matrix

\begin{tabular}{|l|l|l|l|}
\cline { 2 - 4 } \multicolumn{1}{c|}{} & $\mathbf{I}_{\mathbf{1}}$ (years) & $\mathbf{I}_{\mathbf{2}}$ (million $\$$ & $\mathbf{I}_{\mathbf{3}}$ (tones) \\
\hline 1. Period & 5 & 100 & 75 \\
\hline 2. Period & 6 & 230 & 12 \\
\hline 3. Period & 7 & 170 & 48 \\
\hline 4. Period & 6 & 170 & 69 \\
\hline 5. Period & 8 & 400 & 80 \\
\hline 6. Period & 8 & 300 & 160 \\
\hline
\end{tabular}

Step 3: Establishing Relative Importance

Establishing relative importance $\left(\mathrm{w}_{\mathrm{j}}\right)$ of the criterion consists of multiplication the matrix values by the normalized weights for each criterion. Normalized weights of the criterions are found with a ten point scale.

\begin{tabular}{|c|c|c|}
\hline & $\begin{array}{l}\text { Points } \\
\text { out of } \\
10\end{array}$ & $\begin{array}{l}\text { Norma- } \\
\text { lized } \\
\text { Values }\end{array}$ \\
\hline $\mathrm{I}_{1}$ & 6 & 0.32 \\
\hline $\mathrm{I}_{2}$ & 8 & 0.42 \\
\hline $\mathrm{I}_{3}$ & 5 & 0.26 \\
\hline Total & 19 & 1 \\
\hline
\end{tabular}

\begin{tabular}{|l|l|l|l|}
\hline & $\mathbf{I}_{\mathbf{1}}$ & $\mathbf{I}_{\mathbf{2}}$ & $\mathbf{I}_{\mathbf{3}}$ \\
\hline 1. Period & 0.096 & 0.067 & 0.091 \\
\hline 2. Period & 0.115 & 0.155 & 0.013 \\
\hline 3. Period & 0.134 & 0.113 & 0.057 \\
\hline 4. Period & 0.115 & 0.113 & 0.083 \\
\hline 5. Period & 0.153 & 0.273 & 0.096 \\
\hline 6. Period & 0.153 & 0.205 & 0.195 \\
\hline
\end{tabular}

Step 5: Obtaining the Separation Measures

The separation of each alternative from the ideal one is given by Euclidean distance.

$\mathrm{S}_{\mathrm{i}}^{+}=\sqrt{\sum_{i=1}^{k}\left(x_{i j}-x_{j}^{+}\right)^{2}}$ and $\mathrm{S}_{\mathrm{i}}^{-}=\sqrt{\sum_{i=1}^{k}\left(x_{i j}-x_{j}^{-}\right)^{2}}$
Step 2: Non-Dimensionalizing the Center Values in the Evaluation Matrix

$$
\mathrm{Z}_{\mathrm{ij}}=\mathrm{y}_{\mathrm{ij}} / \sqrt{\sum_{i=1}^{n} y_{i j}^{2}}
$$

\begin{tabular}{|l|l|l|l|}
\cline { 2 - 4 } \multicolumn{1}{c|}{} & $\mathbf{I}_{\mathbf{1}}$ (years) & $\mathbf{I}_{\mathbf{2}}$ (million $\$$ ) & $\mathbf{I}_{\mathbf{3}}$ (tones) \\
\hline 1. Period & 0.30 & 0.16 & 0.35 \\
\hline 2. Period & 0.36 & 0.37 & 0.05 \\
\hline 3. Period & 0.42 & 0.27 & 0.22 \\
\hline 4. Period & 0.36 & 0.27 & 0.32 \\
\hline 5. Period & 0.48 & 0.65 & 0.37 \\
\hline 6. Period & 0.48 & 0.49 & 0.75 \\
\hline
\end{tabular}

Step 4: Building Positive and Negative Ideal Solutions

The positive ideal solution corresponds to the set of best or maximum values of each column. Conversely, the negative ideal solution constitutes the set of worst or minimum values of each column of the evaluation matrix where A+ and A- are the set of maximum and minimum values of the criteria's.

\begin{tabular}{|l|l|l|l|}
\cline { 2 - 4 } \multicolumn{1}{c|}{} & $\mathbf{I}_{\mathbf{1}}$ (years) & $\mathbf{I}_{\mathbf{2}}$ (million $\$$ ) & $\mathbf{I}_{\mathbf{3}}$ (tones) \\
\hline 1. Period & 0.096 & 0.067 & 0.091 \\
\hline 2. Period & 0.115 & 0.155 & 0.013 \\
\hline 3. Period & 0.134 & 0.113 & 0.057 \\
\hline 4. Period & 0.115 & 0.113 & 0.083 \\
\hline 5. Period & 0.153 & 0.273 & 0.096 \\
\hline 6. Period & 0.153 & 0.205 & 0.195 \\
\hline
\end{tabular}

$\mathbf{A}^{+}=\{0.153,0.273,0.195\} \quad \mathbf{A}^{-}=\{0.096,0.67,0.013\}$

Step 6: Relative Closeness to the Ideal Solution

Relative closeness to the ideal solution may call overall or composite performance score of the each alternative.,

$\mathrm{C}_{\mathrm{i}}=\mathrm{S}_{\mathrm{i}}^{-} /\left(\mathrm{S}_{\mathrm{i}}^{+}+\mathrm{S}_{\mathrm{i}}^{-}\right)$

$\begin{array}{lll}\mathrm{C}_{1}=0.26 & \mathrm{C}_{2}=0.29 & \mathrm{C}_{3}=0.25 \\ \mathrm{C}_{4}=0.29 & \mathrm{C}_{5}=0.70 & \mathrm{C}_{6}=0.79\end{array}$

Fig. 2. Applying TOPSIS steps to the case-1 


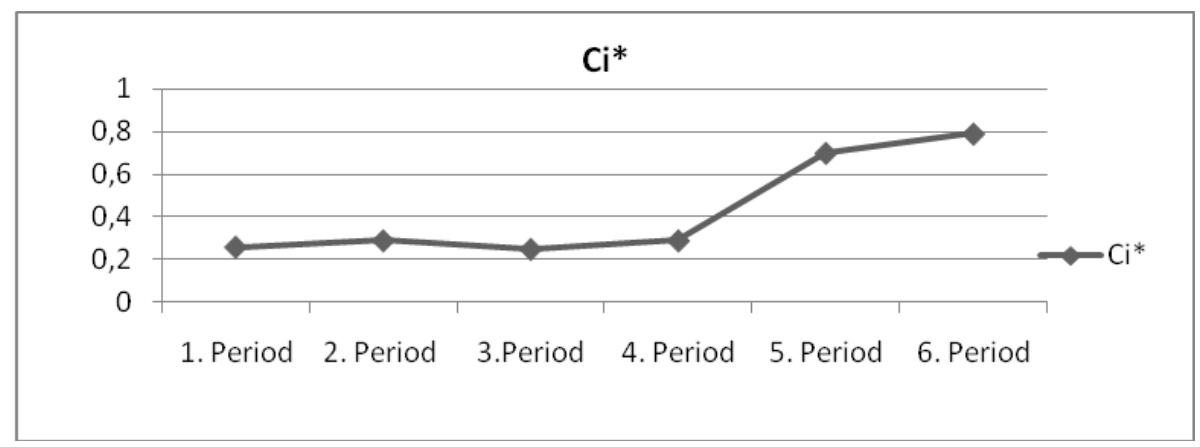

Fig. 3. Performance Values for Each Period

Table 1. Product Data

\begin{tabular}{l|lllll|}
\multicolumn{2}{c}{$\begin{array}{r}\text { Demand } \\
\text { (yearly) }\end{array}$} & $\begin{array}{l}\text { Price } \\
\text { (per product) }\end{array}$ & $\begin{array}{l}\text { Production Duration } \\
\text { (of 1 product) }\end{array}$ & $\begin{array}{l}\text { Recyclability } \\
(\%)\end{array}$ & $\begin{array}{l}\mathrm{CO}_{2} \text { Emission } \\
\text { (yearly) }\end{array}$ \\
\cline { 3 - 7 } A & 300 & 5000 & $8 \mathrm{hr}$ & $75 \%$ & 25 \\
B & 400 & 3000 & $11 \mathrm{hr}$ & $85 \%$ & 40 \\
C & 200 & 5000 & $5 \mathrm{hr}$ & $70 \%$ & 30 \\
D & 300 & 10000 & $8 \mathrm{hr}$ & $50 \%$ & 45 \\
E & 100 & 20000 & $12 \mathrm{hr}$ & $68 \%$ & 20 \\
F & 600 & 3000 & $6 \mathrm{hr}$ & $90 \%$ & 32 \\
\hline
\end{tabular}

$\mathrm{D}, \mathrm{E}$ and $\mathrm{F}$ are shown in Table 1. Data related to production of the six eco-products: annual revenue calculated as multiplication of yearly demand and price per product. For example, from product A: $300 * 5000=1500000$. Revenue from eco-product determined as 10500000 and total revenue of the firm recorded as 19500000. The firm produces 12 hour in a day and 5 days in a week. Recycled material costs 600 and normal material costs 1000 . According to Company X, the product with the maximum revenue, shortest production time, involves larger amount of recyclable material and with minimum amount of carbon emission is preferable.

Using the information gathered by Company $\mathrm{X}$ for 6 products, TOPSIS method was applied as shown in Fig. 4 and summarized in Fig. 5. In the third step, weights are determined according to following calculations; Revenue from eco-products: revenue from eco-products $/$ total revenue $=10.5 / 19.5=0.54 ; 12 \mathrm{hr}$ production in a day and 5 days in a week, $50 \mathrm{hr}$ production of eco-products : $50 / 60=0.83$; Recycled material costs 600 , normal material costs $1000: 1000 / 600=1.66$; It means that if the firm spends 1000 on normal material, they produce 1 product; if they spend same value on recycled material they produce 1.66 products; Mass fraction of greenhouse gases: total mass of CO2 equivalents/ total mass of products $=192 / 1900=0.10$. The results of TOPSIS revealed that product F is more suitable for Company X's policy of sustainability. If the data is reviewed, it is seen that the product $\mathrm{F}$ shows highest 
Step 1: Building the Evaluation Matrix

\begin{tabular}{|l|l|l|l|l|}
\hline & $\begin{array}{l}\text { Revenue } \\
\left(\mathbf{I}_{\mathbf{1}}\right)\end{array}$ & $\begin{array}{l}\text { Time } \\
\left(\mathbf{I}_{\mathbf{2}}\right)\end{array}$ & $\begin{array}{l}\text { Recycling } \\
\left(\mathbf{I}_{3}\right)\end{array}$ & $\begin{array}{l}\mathbf{C O}_{2} \\
\mathbf{E m i s s i o n ~}_{\left(\mathbf{I}_{\mathbf{4}}\right)}\end{array}$ \\
\hline A & 15 & 8 & 75 & 25 \\
\hline B & 12 & 11 & 85 & 40 \\
\hline C & 10 & 5 & 70 & 30 \\
\hline D & 30 & 8 & 50 & 45 \\
\hline E & 20 & 12 & 68 & 20 \\
\hline F & 18 & 6 & 90 & 32 \\
\hline
\end{tabular}

Step 3: Establishing Relative Importance

Establishing relative importance $\left(\mathrm{w}_{\mathrm{j}}\right)$ of the criterion consists of multiplication the matrix values by the normalized weights for each criterion.

\begin{tabular}{|l|l|l|l|l|l|}
\cline { 2 - 6 } \multicolumn{1}{c|}{} & $\mathrm{I}_{1}$ & $\mathrm{I}_{2}$ & $\mathrm{I}_{3}$ & $\mathrm{I}_{4}$ & Total \\
\hline Calculated Weights & 0,54 & 0,83 & 1,66 & 0,1 & 3,13 \\
\hline Normalized Values & 0,17 & 0,27 & 0,53 & 0,03 & 1 \\
\hline
\end{tabular}

\begin{tabular}{|l|l|l|l|l|}
\hline & $\mathbf{I}_{\mathbf{1}}$ & $\mathbf{I}_{\mathbf{2}}$ & $\mathbf{I}_{\mathbf{3}}$ & $\mathbf{I}_{\mathbf{4}}$ \\
\hline $\mathbf{A}$ & 0.056 & 0.099 & 0.217 & 0.009 \\
\hline $\mathbf{B}$ & 0.044 & 0.140 & 0.249 & 0.014 \\
\hline C & 0.037 & 0.062 & 0.201 & 0.011 \\
\hline D & 0.112 & 0.099 & 0.143 & 0.016 \\
\hline E & 0.074 & 0.151 & 0.196 & 0.007 \\
\hline F & 0.066 & 0.075 & 0.259 & 0.012 \\
\hline
\end{tabular}

Step 5: Obtaining the Separation Measures

The separation of each alternative from the ideal one is given by Euclidean distance.

$$
\begin{aligned}
& \mathrm{S}_{\mathrm{i}}^{+}=\sqrt{\sum_{i=1}^{k}\left(x_{i j}-x_{j}^{+}\right)^{2}} \text { and } \mathrm{S}_{\mathrm{i}}^{-}= \\
& \sqrt{\sum_{i=1}^{k}\left(x_{i j}-x_{j}^{-}\right)^{2}}
\end{aligned}
$$

Step 2: Non-Dimensionalizing the Center Values in the Evaluation Matrix

$$
\mathrm{Z}_{\mathrm{ij}}=\mathrm{y}_{\mathrm{ij}} / \sqrt{\sum_{i=1}^{n} y_{i j}^{2}}
$$

\begin{tabular}{|l|l|l|l|l|}
\hline & $\mathbf{I}_{\mathbf{1}}$ & $\mathbf{I}_{\mathbf{2}}$ & $\mathbf{I}_{\mathbf{3}}$ & $\mathbf{I}_{\mathbf{4}}$ \\
\hline $\mathbf{A}$ & 0.33 & 0.37 & 0.41 & 0.31 \\
\hline $\mathbf{B}$ & 0.26 & 0.52 & 0.47 & 0.49 \\
\hline $\mathbf{C}$ & 0.22 & 0.23 & 0.38 & 0.37 \\
\hline $\mathbf{D}$ & 0.66 & 0.37 & 0.27 & 0.55 \\
\hline $\mathbf{E}$ & 0.44 & 0.56 & 0.37 & 0.25 \\
\hline F & 0.39 & 0.28 & 0.49 & 0.39 \\
\hline
\end{tabular}

Step 4: Building Positive and Negative Ideal Solutions

The positive ideal solution corresponds to the set of best or maximum values of each column. Conversely, the negative ideal solution constitutes the set of worst or minimum values of each column of the evaluation matrix where $\mathrm{A}+$ and $\mathrm{A}$ - are the set of best and worst values of the criteria's.

\begin{tabular}{|l|l|l|l|l|}
\hline & $\mathbf{I}_{\mathbf{1}}$ & $\mathbf{I}_{\mathbf{2}}$ & $\mathbf{I}_{\mathbf{3}}$ & $\mathbf{I}_{\mathbf{4}}$ \\
\hline A & 0.056 & 0.099 & 0.217 & 0.009 \\
\hline B & 0.044 & 0.140 & 0.249 & 0.014 \\
\hline C & 0.037 & 0.062 & 0.201 & 0.011 \\
\hline D & 0.112 & 0.099 & 0.143 & 0.016 \\
\hline E & 0.074 & 0.151 & 0.196 & 0.007 \\
\hline F & 0.066 & 0.075 & 0.259 & 0.012 \\
\hline
\end{tabular}

$$
\mathbf{A}^{+}=\{0.112,0.062,0.259,0.007\}
$$

$\mathbf{A}^{-}=\{0.037,0.151,0.143,0.016\}$

\section{Step 6: Relative Closeness to the Ideal Solution}

Relative closeness to the ideal solution may call overall or composite performance score of the each alternative.,

$\mathrm{C}_{\mathrm{i}}=\mathrm{S}_{\mathrm{i}}^{-} /\left(\mathrm{S}_{\mathrm{i}}^{+}+\mathrm{S}_{\mathrm{i}}^{-}\right)$

$\mathrm{C}_{\mathrm{A}}=0.54 \quad \mathrm{C}_{\mathrm{B}}=0.50 \quad \mathrm{C}_{\mathrm{C}}=0.52$

$\mathrm{C}_{\mathrm{D}}=0.43 \quad \mathrm{C}_{\mathrm{E}}=0.36 \quad \mathrm{C}_{\mathrm{F}}=0.75$

Fig. 4. Applying TOPSIS steps to the case-2

performance in production time and recyclability out of remaining products. Moreover production time and recyclability have the highest weights out of the other criterions. It is also seen from the graph that products $\mathrm{A}, \mathrm{B}$ and $\mathrm{C}$ shows similar performance according to the firm's philosophy of sustainability. 


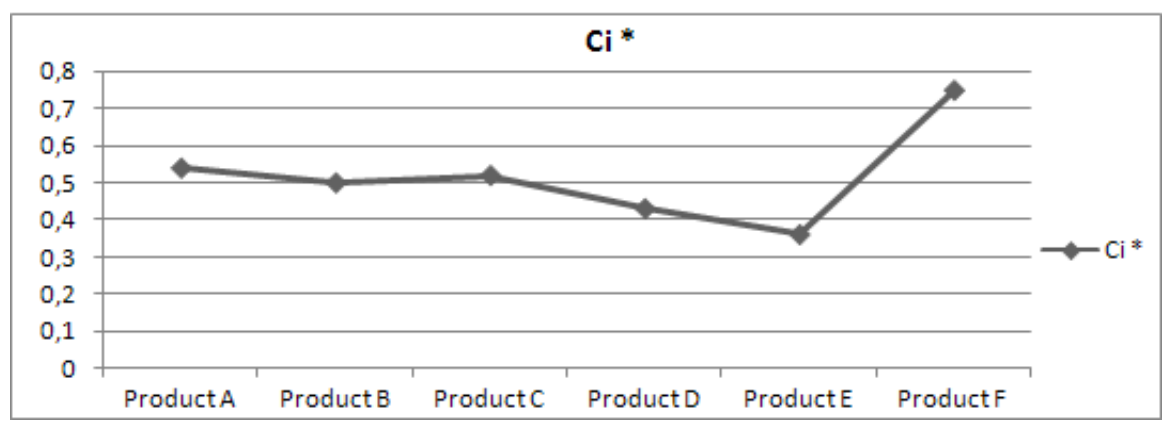

Fig. 5. Performance Values of Each Product

\section{Conclusion}

Since importance of sustainability has been increased, companies have shown more tend to manufacture their products in sustainable way. As a result of this tendency to sustainable manufacturing, the creation of sustainability indicators became a hot topic among researchers. Hence the need to measure and evaluate become prominent, the application of indicators in performance evaluation has been ignored. Specifically, this study focused on usage of sustainable manufacturing indicators for performance evaluation and case studies concerning the application of the TOPSIS method which provides advantages of sufficiency and simplicity while identifying the most suitable alternative quickly in case of the conflicting criterion. Future studies will include complex case studies that contain multi-criteria decision making problem of a real company with the real data. Additionally, to reflect the vagueness concept of sustainability, fuzzy TOPSIS will be applied on sustainability indicators and to analyze the outputs of the fuzzy TOPSIS, sensitivity analysis will be used.

\section{References}

1. Westkamper, E.: Manufuture and Sustainable Manufacturing. In: Manufacturing Systems and Technologies for the New Frontier. The 41st CIRP Conference on Manufacturing Systems, pp. 11-14 (2008)

2. OECD, Organization for Economic Co-operation and Development. Sustainable Manufacturing Indicators, http: / /www. oecd. org/document / 48 / 0,3746, en_21571361_47075996_47855728_1_1_1_1,00.html

3. Raizer Neto, E., Mariotte, M.T., Hinz, R.T.P.: Indicators to Measure Sustainability of an Industrial Manufacturing. In: Innovation in Life Cycle Engineering and Sustainable Development, pp. 111-122 (2006)

4. Krajnc, D., Glavic, P.: Indicators of Sustainable Production. Clean Techn. Environ. Policy 5, 279-288 (2003), doi:10.1007/S10098-003-0221-Z

5. United Nations, Indicators of Sustainable Development: Guidance and Methodologies, 3rd edn. United Nations Publication, Sales No. E.08.II.A.2 (2007) ISBN 978-92-1-104577-2

6. Hwang, C.L., Yoon, K.: Multiple Attribute Decision Making: Methods and Applications. Springer, New York (1981) 